\title{
Oxidative Stress and Antioxidant Enzymes in Pre-eclampsia
}

\author{
${ }^{1}$ Shazia Parveen, ${ }^{2}$ Nasreen Noor, ${ }^{3}$ Shagufta Moin, ${ }^{4}$ Zakia Arshad, ${ }^{5}$ Naheed Banu
}

\section{ABSTRACT}

Objective: To estimate the levels of lipid peroxidation product and free radical metabolizing enzymes in normotensive pregnant women and women with pre-eclampsia.

Materials and methods: The study has been conducted on 50 women between the age group of 20 and 35 years. The women were divided into two groups, i.e. group A - normotensive pregnant women between 20 and 36 weeks of gestation and group B-Pregnant women with pre-eclampsia between 20 and 36 weeks of gestation. Lipid peroxidation product malondialdehyde (MDA) and antioxidant enzymes SOD, GSH and GST were estimated.

Results: Mean circulating levels of MDA were higher in women with pre-eclampsia as compared to normotensive pregnant women and mean circulating levels of free radical metabolizing enzymes SOD, GSH and GST were decreased in women with pre-eclampsia.

Conclusion: Pre-eclampsia is a state of pregnancy in which there is increased oxidative stress an depicted by increased level of free radical MDA and decreased levels of antioxidant enzyme to counter act that oxidative stress.

Keywords: Pre-eclampsia, Lipid peroxidation, Antioxidants.

How to cite this article: Parveen S, Noor N, Moin S, Arshad Z, Banu N. Oxidative Stress and Antioxidant Enzymes in Preeclampsia. J South Asian Feder Obst Gynae 2014;6(1):5-7.

Source of support: Nil

Conflict of interest: None

\section{INTRODUCTION}

Pregnancy is a physiological state where there is stress and many biochemical changes in the body. Hypertensive disorders, complicating pregnancy are common and form one

\footnotetext{
${ }^{1,2}$ Assistant Professor, ${ }^{3}$ Associate Professor, ${ }^{4}$ Ex-Professor ${ }^{5}$ Professor

${ }^{1,2,4}$ Department of Obstetrics and Gynecology, Jawaharlal Nehru Medical College and Hospital, Aligarh Muslim University Aligarh, Uttar Pradesh, India

${ }^{3}$ Department of Biochemistry, Jawaharlal Nehru Medical College and Hospital, Aligarh Muslim University, Aligarh, Uttar Pradesh, India

${ }^{5}$ Department of Biochemistry, Faculty of Life Sciences Jawaharlal Nehru Medical College and Hospital, Aligarh Muslim University, Aligarh, Uttar Pradesh, India
}

Corresponding Author: Shazia Parveen, Assistant Professor Department of Obstetrics and Gynecology, Jawaharlal Nehru Medical College and Hospital, Aligarh Muslim University Aligarh, Uttar Pradesh, India, e-mail: shzparveen@gmail.com of the deadly triad along with hemorrhage and infection, that results in much of mortality and morbidity. Pre-eclampsia is defined as increased blood pressure more than 140/90 $\mathrm{mm} \mathrm{Hg}$ and along with proteinuria, pre-eclampsia affects around 3 to $5 \%$ of pregnancies and can have a significant impact on the health of mother of fetus. ${ }^{1}$ The disease is usually diagnosed late in pregnancy although the cause of the disease is not known but there is close association between lipid peroxidation and pre-eclampsia.

Malondiadehyde (MDA) is an end product of lipid peroxidation. MDA levels increase beyond normal pregnancy levels by second trimester in pre-eclampsia. ${ }^{2,3}$

Imbalance between reactive oxygen species and antioxidants appears to be an important contributing factor. ${ }^{4,5}$ Increased reactive oxygen species act upon the cellular DNA lipid to produce oxidized DNA and lipid peroxides. Polyunsaturated fatty acids upon peroxidation produces MDA. Oxidative stress increase during pre-eclampsia ${ }^{6}$ and there is compromise of antioxidants. ${ }^{7-10}$ The antioxidant system comprises of vitamins and antioxidant enzymes. The present study was carried out to see the levels of lipid proxidation product MDA and antioxidant enzymes superoxide dismutase (SOD), Glutathione S-transferase (GST) and (GSH) level in normal pregnancy and in pregnancy associated with pre-eclampsia.

\section{MATERIALS AND METHODS}

The study was conducted on the women attending the OPD and IPD in Department of Obstetrics and Gynecology of Jawaharlal Nehru Medical College and Hospital, Aligarh Muslim University, Aligarh, after obtaining ethical approval from the institute. The study was prospective observational type.

For the present study, 50 women between the age group of 20 to 35 years were selected. Changes in antioxidant status was assessed and correlated with increase free radical activity to determine their role in the pathogenesis of preeclampsia. After obtaining informed consent, blood samples were collected from normotensive pregnant women and women diagnosed with pre-eclampsia. Apart from Investigations of PIH profile, $5 \mathrm{ml}$ blood was taken from each women in vials containing heparin. The samples were centrifuged at $3000 \mathrm{rpm}$ for 15 minutes - plasma was collected and RBCs were washed three times with $0.9 \%$ normal saline all samples were refrigerated until assayed. To assess 
Table 1: Base line parameters in normotensive pregnant women and women with pre-eclampsia

\begin{tabular}{lcc}
\hline Parameters & $\begin{array}{c}\text { Normotensive pregnant women } \\
\text { (Group A) }(N=25)\end{array}$ & $\begin{array}{c}\text { Pregnant women with pre-eclampsia } \\
\text { (Group B) }(N=25)\end{array}$ \\
\hline Mean age (years) & $23.5 \pm 2$ & $24.7 \pm 3.2$ \\
Mean height (cm) & $149 \pm 5.1$ & $152 \pm 6.1$ \\
Mean weight (kg) & $61.8 \pm 5.6$ & $63.8 \pm 4.4$ \\
Mean parity & $0.72 \pm 1.1$ & $0.4 \pm 0.8$ \\
Mean systolic BP (mm Hg) & $115.4 \pm 6.1$ & $141 \pm 9.3$ \\
Mean diastolic BP (mm Hg) & $72.2 \pm 7.9$ & $94.2 \pm 5.7$ \\
Mean platelet count (Lac/cumm) & $2.38 \pm 0.7$ & $1.8 \pm 0.8$ \\
Baby birth weight (kg) & $2.87 \pm 0.4$ & $2.64 \pm 0.6$ \\
Mean apgar score & $8.9 \pm 0.6$ & $8.2 \pm 1.7$ \\
Serum uric acid (mg\%) & $4.62 \pm 0.3$ & $5.4 \pm 0.9$ \\
\hline
\end{tabular}

the oxidative stress erythrocyte MDA, SOD activity, GST activity and GSH levels were estimated in women with preeclampsia and were compared with normotensive pregnant women matched for gestational age serving as control.

The cases were divided into two groups:

1. Group A: 25 normotensive pregnant women between 20 to 36 weeks of gestation.

2. Group B: 25 women with pre-eclampsia between 20 to 36 weeks of gestation.

Comparison was done in the levels between normal pregnant and pre-eclamptic women.

Statistics: Student ' $t$ ' was applied for statistical analysis.

\section{RESULTS}

Maximum number of women in both the groups belonged to 20 to 25 years of age, 150 to $160 \mathrm{~cm}$ in height and 60 to 70 $\mathrm{kg}$ of body weight. Mean BMI of group A was 26.5 and of group B was 27.4. Mean parity in group A was 0.72 and in group B was 0.4. Significant difference in systolic BP was observed when group A was compared with group $B$, mean systolic BP of group A was 115.4 and of group B was 141. Similarly significant difference in diastolic BP was observed when both groups were compared, the mean diastolic BP of group A was $72.2 \mathrm{~mm} \mathrm{Hg}$ and of group B was $94.2 \mathrm{~mm}$ $\mathrm{Hg}$. The mean platelet count in group A was $2.38 \mathrm{Lac} /$ cumm and of group B was $1.8 \mathrm{Lac} /$ cumm and the difference was

Table 2: Circulating levels of MDA, SOD, GST and GSH in normotensive pregnant women and pregnant women with preeclampsia

\begin{tabular}{llll}
\hline $\begin{array}{l}\text { Lipid per oxidation } \\
\text { product and } \\
\text { antioxidant enzyme } \\
\text { leve/s }\end{array}$ & Group A & Group B & $p$-value \\
\hline MDA (mmole/liter) & $5.75 \pm 1.88$ & $10.71 \pm 2.65$ & $<0.001$ \\
$\begin{array}{l}\text { SOD (units/mg of } \\
\text { protein) }\end{array}$ & $4.7 \pm 1.5$ & $2.81 \pm 0.52$ & $<0.001$ \\
$\begin{array}{l}\text { GST (nmole/mg of } \\
\text { protein) }\end{array}$ & $16.92 \pm 2.4$ & $12.54 \pm 2.67$ & $<0.001$ \\
$\begin{array}{l}\text { GSH ( } \mu \text { mole/mg of } \\
\text { protein) }\end{array}$ & $0.6 \pm 0.14$ & $0.22 \pm 0.12$ & $<0.05$ \\
\hline
\end{tabular}

statistically significant when the groups were compared. In group A majority of women delivered vaginally while in group B majority delivered by cesarean section. Mean serum uric acid level in group A was $4.5 \mathrm{mg} \%$ and in group B was $5.4 \mathrm{mg} \%$. Mean apgar score in group A was 8.9 and in group B was 8.2 (Table 1).

Mean circulating levels of MDA in group A was $5.75 \pm$ $1.88 \mathrm{mmole} / \mathrm{l}$, in group B it was $10.71 \pm 2.65$ and difference was statistically significant. Mean circulating levels of SOD in group A was $4.7 \pm 1.5$ units $/ \mathrm{mg}$ of protein, in group B it was $2.8 \pm 0.52$ units $/ \mathrm{mg}$ of protein and the difference was statistically significant. Mean circulating levels of GST in group A was $16.92 \pm 2.4 \mathrm{nmole} / \mathrm{mg}$ of protein and in group B it was $12.54 \pm 2.67 \mathrm{nmole} / \mathrm{mg}$ of protein and the difference was statically significant. Mean circulating levels of GSH in group A was $0.6 \pm 0.14 \mu \mathrm{mole} / \mathrm{mg}$ of protein and in group B it was $0.22 \pm 0.12 \mu \mathrm{mole} / \mathrm{mg}$ of protein and the difference was statistically significant (Table 2 ).

\section{DISCUSSION}

Pre-eclampsia is a leading cause of maternal and fetal morbidity it causes preterm deliveries and intrauterine growth retardation. Pre-eclampsia is characterized by increase blood pressure associated with proteinuria diagnosed usually in second and third trimester of pregnancy although exact etiology of the disease is not known but several researches have pointed toward it association with lipid peroxidation and endothelial cell dysfunction we have observed significant increase in MDA levels (a lipid peroxidation product) in pre-eclamptic women as compared to normotensive pregnant women also observed by other workers. ${ }^{11,12}$ But some studies have shown no evidence of increase lipid peroxidation in pre-eclampsia. Madazli in 1999 has shown that concentration of lipid peroxide are increased in pre-eclampsia while the concentration of water and lipid soluble antioxidants are decreased in plasma of women with pre-eclampsia, we have observed the similar result, i.e. the concentration of SOD, GST and GSH were decreased significantly in women 
with pre-eclampsia as compared to normotensive pregnant women.

We conclude from this study that lipid peroxidation plays a major role in the pathogenesis of pre-eclampsia to prevent the pathology more of the antioxidants are utilized and hence the level of antioxidants decrease in the disease as depicted by the decreased level of antioxidant enzymes in pre-eclampsia.

\section{REFERENCES}

1. Baum Well S, Ananth Karumanchi S. Pre-eclampsia: Clinical manifestations and molecular mechanism. Nephron Clin Pract 2007;106(2):C72-81.

2. Atamera Y, Ko Cyigit Y, Yokura B, Atamere A, Ceylan Erdend A. Eur J Obstet Gynecol Reprod Biol 2005;119(1):60-66.

3. Haque SK, Siddiqui MU, Islam N, Moin S. Esythrocyte markers of oxidative stress in higher age group pre-eclamptic and normal pregnant mothers. Hypertens Pregnancy 2010;29(1):69-81.

4. Kamath U, Rao G, Kamath SU, Rai L. Maternal and fetal indicators of oxidative stress during pregnancy induced hypertension. International J Applied Biology and Pharmaceutical Technology 2011;2(1):405-410.

5. Boutet M, Roland L, Thomas N, Bilodeau JF. Specific systemic antioxidant response to eclampsia in late pregnancy. The study of intracellular glutathione peroxidases in maternal and fetal blood. Am J Obstet Gynecol 2009;200(5):530e1-7.

6. Hubel CA. Oxidative stress in the pathogenesis of pre-eclampsia Proc Soc Exp Biol Med 1999;222:222-235.

7. Uotiala JT, Tuimala RJ, Aarnio TM, Pyykko KA, Ahotupa MO. Findings on lipid peroxidation and antioxidant function in hypertensive complications of pregnancy. Br J Obstet Gynaecol 1993;100:270-276.

8. Chen G, Wilson R, Cumming G, Walker JJ, Smith WE, Mckillop $\mathrm{JH}$. Intracellular and extracellular antioxidant buffering levels in erythrocytes from pregnancy induced hypertension. J Hum Hypertens 1994;8:37-42.

9. Mikhail MS, Anyaegbunam A, Garfinkel D, Palan PR, Basu J, Romney SL. Pre-eclampsia and antioxidant nutrients: decreased plasma levels of reduced ascorbic acid, alpha-tocopherol and beta-carotene in women with pre-eclampsia. Am J Obstet Gynecol 1994;171:150-157.

10. Madazli R, Benian A, Gumustas K, Uzun H, Ocak V, Aksu F. Lipid peroxidation and antioxidants in pre-eclampsia. Eur $\mathrm{J}$ Obstet Gynecol Reprod Biol 1999;85:205-208.

11. Mohanty S, Sahu PK, Mandal MK, Mohapatra PC, Panda A. Evaluation of oxidative stress in pregnancy induced hypertension. Indian J Clin Biochemistry 2006;21(1): 101-105.

12. Tayal D, Tripathi R, Khaneja A. Comparative study of nitric oxide and malondialdehyde in pregnancy induced hypertension, normal pregnant and nonpregnant women. Research J Pharmaceutical; Bio Chem Sciences 2011;2(2): 749-753. 